\title{
Functional studies of the parotid and pancreas glands in amyotrophic lateral sclerosis
}

\author{
R. J. CHARCHAFLIE, L. BUSTOS FERNANDEZ, C. J. PEREC, ${ }^{1}$ \\ E. GONZALEZ, AND A. MARZI \\ From Cátedra de Neurología, Facultad de Medicina, Universidad de Buenos Aires, \\ Instituto de Gastroenterología J. Perez Companc, U.C.A. and Cátedra de Fisiología, \\ Facultad de Odontología, Universidad de Buenos Aires, Argentina
}

SYNOPSIS Functional studies of the pancreas and parotid glands are reported in 17 patients with amyotrophic lateral sclerosis (ALS). The exocrine function of the pancreas was studied by measuring amylase concentration after stimulation with the endogenous secretin-pancreozymine test (ESP). Under these conditions, the pancreatic amylase concentration in ALS patients was found to be markedly decreased by about $45 \%$ when compared with those of healthy control subjects. Different conclusions in the literature about a possible impairment of the exocrine pancreas in ALS patients induced us to study the function of the parotid gland, which has close structural, functional, and physiopathological relationship with the pancreas. Flow rate and bicarbonate concentration of parotid saliva were measured after indirect stimulation (intraoral citric acid) and direct stimulation (pilocarpine). After indirect stimulation, both parotid flow rate and bicarbonate concentration from ALS patients were found to be decreased by about $66 \%$ and $70 \%$ respectively, when compared with controls. On the other hand, direct stimulation with pilocarpine in ALS patients elicited normal responses in both flow rate and bicarbonate concentration of saliva. It is concluded that the pancreatic and parotid deficiencies observed in ALS patients do not indicate primary disease of these exocrine glands. This interpretation is further emphasized by the results obtained by a sweat test, plasma osmolarity, and sialographic studies. The possibility that the gland impairments observed might be due to modifications of the neuroendocrine mechanisms regulating their secretory activity is suggested.

Although numerous studies have been reported on the aetiology of amyotrophic lateral sclerosis (ALS), the cause of this progressively lethal disease remains unknown (Norris et al., 1968). In some ALS patients digestive disturbances have been observed. Thus, Quick and Greer (1966) found in the duodenal juice of ALS patients a decreased concentration of bicarbonate after stimulation with secretin and they suggested a beneficial response in some of their patients if treated with pancreatic extract. On the other hand, McEwan Alvarado et al. (1971) reported normal pancreatic responses to the secretin test in eight patients with ALS.

The present study was undertaken in order to

1 Reprints: Dr C. J. Perec, Cátedra de Fisiología, Facultad de Odontología, Charcas 2142, Buenos Aires, Argentina. establish whether in ALS patients the exocrine pancreatic tissue is primarily involved or if the gland dysfunction might follow an impairment of other factors which participate in the mechanism of the pancreatic secretory response (hormonal and nervous influences). For this purpose, in a group of ALS patients the pancreatic exocrine function was studied by the endogenous secretin-pancreozymine test (ESP test). This technique evaluates not only pancreatic functional mass but digestive hormonal functional activity and probably neuronal tone which mediates the exocrine and endocrine secretion (Tiscornia et al., 1971).

In addition, and based upon structural, functional, and physiopathological similarities between the pancreas and the parotid gland (Roth- 
bell and Duggan, 1957; Wolfe et al., 1957) we investigated the flow rate and bicarbonate concentration in parotid saliva from ALS patients after direct and indirect stimulation.

\section{METHODS}

In patients with a diagnosis of ALS based on clinical and electromyographic studies (Table 1), the exocrine pancreatic function was investigated with the ESP test, performed according to the technique described by Tiscornia et al. (1971). The functional capacity of the parotid gland was studied by measuring the secretory flow rate and bicarbonate concentration in the saliva secreted in response to stimulation either through the gustatory unconditioned salivary reflex (intraoral citric acid) or directly by administration of pilocarpine. The ESP test was done in 14 ALS patients and in 10 healthy normal subjects (control group) after a 12 hours fasting period. For this purpose, and under fluoroscopic control, a Dreiling catheter was placed in the duodenum according to conventional methods. An acidified peptonated broth, prepared with $5 \mathrm{~g}$ meat extract (Bovril), $95 \mathrm{ml}$ distilled water, and $\mathrm{HCl} 10$ $\mathrm{mEq}$ was instilled through the catheter into the duodenum. The mixture was previously warmed to $37^{\circ} \mathrm{C}$ and slowly perfused during five minutes with the flask at the same level as the patient's bed. Amylase concentration in the duodenal juice was determined by the method of Dahlquist (1962); aliquots of the total volume obtained 20 minutes after the stimulation (maximal peak) were drawn and measured. Values were calculated in units $/ \mathrm{ml} / \mathrm{min}$. In 13 ALS patients and in six controls, samples of parotid saliva were collected unilaterally using the vacuum cup, as described by Shannon et al. (1962). In both groups all medication and smoking were suspended during the last 48 and 24 hours, respectively. Each patient stimulated his oral mucosa with $3 \mathrm{ml} 0 \cdot 1 \mathrm{~N}$ citric acid solution without swallowing for 30 seconds. This procedure was repeated twice for 30 seconds, followed on each occasion by 30 seconds' rest. The samples of parotid saliva were collected in calibrated tubes and stored at $0^{\circ} \mathrm{C}$. For the direct stimulation of the parotid gland, five ALS patients and three normal subjects were injected subcutaneously with pilocarpine sulphate $(5 \mathrm{mg})$. After 10 minutes' rest, saliva was collected during five minutes. Flow rate was expressed as $\mathrm{ml} / \mathrm{min}$ and bicarbonate concentration in saliva was determined by using Segal's titrimetric method as modified by Henry (1964) using PSP (phenol red) as indicatore The values obtained are expressed as $\mathrm{mEq} / \mathrm{l}$.

Plasma osmolarity was determined cryoscopicall with the Fiske osmometer. A sweat test to determing sodium concentration was performed in three ALS patients after stimulating with a subcutaneous injection of $5 \mathrm{mg}$ pilocarpine sulphate solution.

TABLE 1

SEX, AGE, TIME OF EVOLUTION, AND CLINICAL SIGNS AT TIME OF PANCREATIC AND PAROTID STUDIES IN PATIENTS WITH AMYOTROPHIC LATERAL SCLEROSIS

\begin{tabular}{|c|c|c|c|c|c|c|c|c|}
\hline \multirow{2}{*}{$\begin{array}{c}\text { Patient } \\
\text { (no.) }\end{array}$} & \multirow{2}{*}{\multicolumn{2}{|c|}{$\begin{array}{l}\text { Sex and } \\
\text { age }(y r)\end{array}$}} & \multirow{2}{*}{$\begin{array}{l}\text { Evolution time } \\
\quad \text { (months) }\end{array}$} & \multirow[t]{2}{*}{ Bulbar } & \multicolumn{2}{|c|}{ Extremities } & \multicolumn{2}{|c|}{ Functional studies } \\
\hline & & & & & Upper & Lower & Pancreas & Parotid \\
\hline 1 & $\mathbf{M}$ & 50 & $1-7$ & 0 & 0 & ++ & yes & yes \\
\hline 2 & $\mathbf{M}$ & 43 & $2-9$ & 0 & ++ & ++ & yes & yes \\
\hline 3 & $\mathbf{M}$ & 68 & 4 & 0 & ++ & ++ & yes & no \\
\hline 4 & $\mathbf{F}$ & 60 & 8-14 & ++ & +++ & +++ & yes & yes \\
\hline 5 & $\mathbf{F}$ & 55 & $11-17$ & ++ & ++ & ++ & yes & yes \\
\hline 6 & $\mathbf{M}$ & 46 & $12-18$ & ++ & +++ & +++ & yes & yes \\
\hline 7 & $\mathbf{F}$ & 55 & $13-19$ & + & +++ & +++ & yes & yes \\
\hline 8 & $\mathbf{M}$ & 48 & 20 & +++ & +++ & +++ & no & yes \\
\hline 9 & $\mathbf{M}$ & 59 & $24-30$ & + & ++ & +++ & yes & yes \\
\hline 10 & $\mathbf{F}$ & 78 & 24 & ++ & +++ & ++ & yes & yes \\
\hline 11 & $\mathbf{F}$ & 52 & 24 & 0 & ++ & +++ & yes & no \\
\hline 12 & $\mathbf{M}$ & 50 & $21-31$ & + & ++ & +++ & yes & no \\
\hline 13 & $\mathbf{F}$ & 83 & $30-36$ & 0 & ++ & + & yes & yes \\
\hline 14 & $\mathbf{M}$ & 54 & 38 & + & ++ & +++ & no & yes \\
\hline 15 & & 22 & 42 & ++ & +++ & ++ & no & yes \\
\hline 16 & $\mathbf{M}$ & 73 & $54-60$ & + & ++ & +++ & yes & yes \\
\hline 17 & $\mathbf{M}$ & 54 & 60 & + & +++ & ++ & yes & no \\
\hline
\end{tabular}

Bulbar signs: 0 Normal. + Jaw reflex increased. ++ Jaw reflex increased plus tongue fasciculation. +++ Jaw reflex increased plus tongue fasciculation plus tongue atrophy and/or dysphagia.

Upper and lower motor neuron signs: 0 Normal. + Increased reflexes and fasciculation. + + Increased reflexes plus atrophy. +++ Increased reflexes plus atrophy plus severe wasting. 
two ALS patients a bilateral sialography of the parotid gland was done by the technique of Ericson (1968).

Care was taken that the ALS patients under study were not affected with a concomitant disease or aetiological factors which could induce pancreatic and/or parotid disturbances (choledololithiasis, alcoholism, endocrine diseases, etc.). Results obtained were in all cases compared with a control group of healthy persons.

The mean and standard error of the mean of the results were calculated for both groups. Significance of the difference between means of the results was tested by using the $t$ index of Student, and the probability determined in the Table of Fisher and Yates (1939). A P of 0.05 was interpreted as significant.

\section{RESULTS}

PANCREATIC RESPONSE (ESP TEST) Results are shown in Table 2. After duodenal stimulation the mean ( $\pm S E$ of mean) of the pancreatic amylase concentration in controls was found to

TABLE 2

AMYLASE CONCENTRATION OF DUODENAL CONTENT AFTER STIMULATION WITH ENDOGEN AND SECRETIN PANCREOZYMINE TEST (ESP)

\begin{tabular}{lcc}
\hline & $\begin{array}{c}\text { Cases } \\
(\text { no. })\end{array}$ & $\begin{array}{c}\text { Amylase concentration } \\
\text { (units/ml/min) }\end{array}$ \\
\hline Controls & 10 & $221 \pm 29 \cdot 7$ \\
ALS patients & 14 & $120 \pm 18 \cdot 9^{*}$ \\
\hline
\end{tabular}

$* \mathrm{P}<0.01$.

be $221 \pm 29 \cdot 7$ units $/ \mathrm{ml} / \mathrm{min}$ (range 125-380). In ALS patients the amylase concentration was markedly decreased, $120 \pm 18.9$ units $/ \mathrm{ml} / \mathrm{min}$ (range 48-305). The difference between the groups was statistically significant $(P<0.01)$.

PAROTID RESPONSE 1. Citric acid stimulation The parotid secretory response elicited after stimulation with citric acid was found to be significantly lower $(P<0.001)$ in the ALS group $(0.24 \pm 0.06$, range 0.01 to $0.70 \mathrm{ml} / \mathrm{min})$ than that of the control group $(0.76 \pm 0.11$ range, 0.46 to $1.3 \mathrm{ml} / \mathrm{min}$ ) (Table 3). Similarly, in the ALS patients the bicarbonate concentration in saliva was significantly decreased $(P<0.01)$ when com-
TABLE 3

PAROTID FLOW RATE AND BICARBONATE CONCENTRATION IN SALIVA AFTER CITRIC ACID STIMULATION*

\begin{tabular}{lccc}
\hline & $\begin{array}{c}\text { Cases } \\
(\text { no. })\end{array}$ & $\begin{array}{c}\text { Flow rate } \\
(\mathrm{ml} / \mathrm{min})\end{array}$ & $\begin{array}{c}\text { Bicarbonate concn } \\
(\mathrm{mEq} / \mathrm{l})\end{array}$ \\
\hline Controls & 6 & $0.76 \pm 0.11$ & $14.5 \pm 3.15$ \\
ALS patients & 13 & $0.24 \pm 0.06 \ddagger$ & $4.0 \pm 0.92 \dagger$ \\
\hline
\end{tabular}

* The statistical study for bicarbonate was performed with the saliva of 10 patients; in the other three ALS patients the volume of saliva obtained was insufficient for the corresponding tests. $\dagger \mathbf{P}<0.01$.

$\ddagger \mathbf{P}<0.001$.

pared with that of healthy subjects, from $14 \cdot 5 \pm$ $3 \cdot 15$ (range 12-30) $\mathrm{mEq} / \mathrm{l}$. in the controls to $4 \cdot 0 \pm 0.92$ (range $1-8$ ) $\mathrm{mEq} / 1$. It should be noticed that the bicarbonate statistics were calculated from the data from only 10 ALS patients, since the insufficient amount of saliva obtained in the other three made bicarbonate determination impossible.

2. Pilocarpine stimulation The decreased flow rate as well as the lowered bicarbonate con-

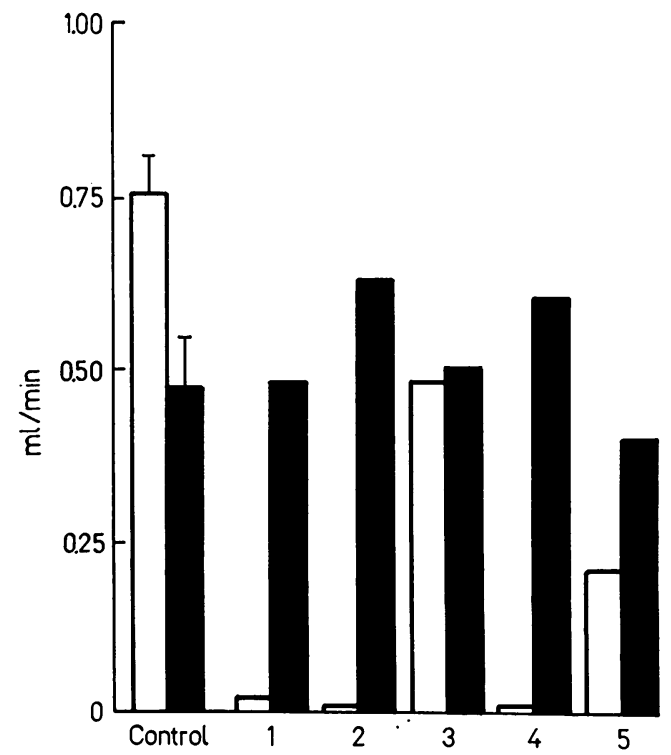

FIG. 1. Flow rate of parotid saliva in $\mathrm{ml} / \mathrm{min}$ from five ALS patients after citric acid stimulation $(\square)$ and pilocarpine $(\square)$. 


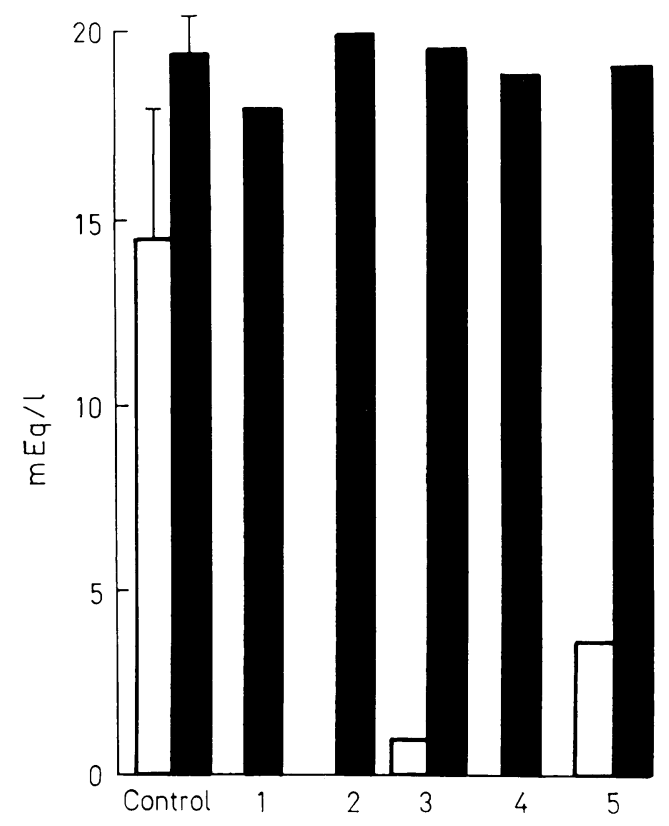

FIG. 2. Bicarbonate concentration $(\mathrm{mEq} / \mathrm{l})$ in parotid saliva from five ALS patients after citric acid stimulation $(\square)$ and pilocarpine $(\square)$.

centration of parotid saliva observed in ALS patients after citric acid stimulation may suggest a functional impairment of the gland. In order to investigate this possibility, it was decided to study both parameters again after direct stimulation with pilocarpine. In five ALS patients after the parotid secretory response to citric acid stimulation vanished, $5 \mathrm{mg}$ pilocarpine sulphate was subcutaneously injected. The individual results of salivary flow rates are shown in Fig. 1. It can be seen that the salivary flow rate in ALS patients after citric acid stimulation was markedly reduced (in patients 1,2 , and 4 nearly absent) as previously mentioned. Yet, in those same patients, the results of the secretory responses elicited by pilocarpine did not differ from the one obtained in controls (Fig. 1). Moreover, after pilocarpine stimulation, the bicarbonate concentration of parotid saliva also reached normal values in ALS patients. On the other hand, after citric acid stimulation patients 3 and 5 showed remarkably low values, while in patients 1,2 , and 4 no measurable bicarbonate could be detected (Fig. 2).
OTHER FUNCTIONAL TESTS (1) Plasma osmolarity: the results obtained in five patients with ALS did not show any difference from normal values: 290-310-295-290 and $295 \mathrm{mEq} / \mathrm{l}$. (2) Sweat test: in the three ALS patients studied, the sweat sodium concentration obtained was within normal values: $26-28$ and $38 \mathrm{mEq} / \mathrm{l}$. Sialography: radiological studies of the parotids in two ALS patients did not show any evidence of organic lesions.

\section{DISCUSSION}

The data presented in this study indicate that after the endogenous secretion pancreozymine (ESP) test there is an insufficient pancreatic exocrine response in ALS patients. Thus, our results are in apparent disagreement with those reported by McEwan-Alvarado et al. (1971), who obtained normal pancreatic responses after secretin stimulation. However, these authors directly stimulated the pancreatic secretoryo activity; the method employed by us involves activation of the neurohormonal mechanisms (vagal tonus, hormonal release, etc.) which leade to pancreatic response. Furthermore, pancreatic amylase and bicarbonate concentration do noto seem to be of reliable functional diagnostic value when the more purified secretins (G.I.H.) are? employed (Gutierrez and Baron, 1972).

The variety of the results reported in the literature (Quick, 1964; McEwan-Alvarado et al., 1971) about the normal or altered pancreatic function in ALS patients, might be attributed to different approaches to study of the gland, by direct or indirect stimulation. The close structural, functional, and physiopathological relationships between the pancreatic and parotid glands are well known (Kakizaki et al., 1973; Del Castillo et al., 1959). It was therefore decided to study parotid function by both direct and indirect stimulation.

The results obtained with pilocarpine (direct stimulation) exclude a primary deficiency of the parotid gland. This would be in agreement with the findings of McEwan-Alvarado et al. (1971) in the pancreas. On the other hand, both parotid and pancreatic glands showed a remarkable functional impairment when stimulated indirectly in ALS patients. In the pancreas, similar results were reported by Quick and Greer (1966). 
The decrease in parotid flow rate observed in ALS patients is not related to extracellular fluid variations, since in the five ALS cases studied the plasma osmolarity values were normal. Moreover, radiological studies did not show any pathological structural changes. The normal responses to the sweat test rule out the possibility of a diffuse involvement of exocrine glands.

Therefore, in the light of our results, we conclude that in ALS patients the pancreatic and parotid deficiencies do not follow a primary disease of the exocrine glands but are more likely to be due to modifications of the neuroendocrine mechanisms which regulate their secretory activity. It is interesting to mention that pancreatic functional insufficiency, as seen in our ALS patients, might be related with the findings of Ask-Upmark (1950) who reported ALS after gastrectomy with the Billroth II type of resection. A possible interpretation of this finding could be that the duodenal exclusion produces a functional pancreatic insufficiency, since the duodenal cells carry the highest concentration of digestive hormones. This interpretation poses the question of whether the pathogenesis of ALS could in some way be related to a functional insufficiency of some of the digestive glands.

We thank Professor T. Insausti for allowing us to study patients under his care and for his kind collaboration. This study was partially supported by Grant No. 3211a/68 from the Consejo Nacional de Investigaciones Científicas y Técnicas, Buenos Aires, Argentina.

\section{REFERENCES}

Ask-Upmark, E. (1950). Amyotrophic lateral sclerosis observed in 5 persons after gastric resection. Gastroenterology, 15, 257-259.
Dahlquist, A. (1962). A method for the determination of amylase in intestinal content. Scandinavian Clinical and Laboratory Investigations, 14, 145-151.

Del Castillo, E. B., Milstein, M., and Jauregui, G. (1959). Aumento del tamaño de las glándulas parótidas y submaxilares en la diabetes mellitus con acromegalia. Medicina (Buenos Aires), 19, 245-248.

Ericson, S. (1968). The parotid gland in subjects with and without rheumatoid arthritis. Acta Radiologica, Suppl. 275, 20-22.

Fisher, R. A., and Yates, F. (1939). Statistical Tables for Biological, Agricultural and Medical Research. 4th ed. Table 39. Oliver and Boyd: Edinburgh.

Gutierrez, L. V., and Baron, J. H. (1972). A comparison of Boots and GIH secretin as stimuli of pancreatic secretion in human subjects with or without chronic pancreatitis. Gut, 13, 721-725.

Henry, R. J. (1964). Clinical Chemistry Principles and Techniques, pp. 462-464. Harper and Row: New York.

Kakizaki, G., Noto, N., Saito, T., Fujiwara, Y., Ohizumi, T., Soeno, T., and Ishidate, T. (1973). Laboratory diagnostic test for pancreatic disorders by examination of parotid saliva. Tokoku Journal of Experimental Medicine, 109, 121133.

McEwan-Alvarado, G., Hightower, N. C., Jr, Carney, L. R., and Barrier, C. W., Jr (1971). Exocrine pancreatic function in patients with amyotrophic lateral sclerosis. American Journal of Digestive Disease, 16, 107-110.

Norris, F. H., Jr, McMenemey, W. H., and Barnard, R. O. (1968). Anterior horn pathology in carcinomatous neuromyopathy compared with other forms of motor neuron disease. In Motor Neuron Diseases, pp. 100-111. Edited by F. H. Norris Jr and L. T. Kurland. Grune and Stratton: New York.

Quick, D. T., and Greer, M. (1966). Pancreatic dysfunction in amyotrophic lateral sclerosis. Neurology (Minneap.), 17, 112-116.

Rothbell, E. N., and Duggan, J. J. (1957). Enlargement of the parotid gland in disease of the liver. American Journal of Medicine, 22, 367-372.

Shannon, I. L., Prigmore, J. R., and Chauncey, H. H. (1962). Modified Carlson-Crittenden device for the collection of parotid fluid. Journal of Dental Research, 41, 778-783.

Tiscornia, O. M., Gonzalez, E., Marzi, A., and Bustos Fernandez, L. (1971). Exploración funcional pancreática exócrina en base a un nuevo test de comida intraduodenal -caldo peptonado acidificado. Semana Médica, 138, 453459.

Wolfe, S. J., Summerskill, W. H., and Davidson, C. S. (1957). Parotid swelling, alcoholism and cirrhosis. New England Journal of Medicine, 256, 491-495. 